\title{
Bile Secretion of Trace Elements in Rats with a Congenital Defect in Hepatobiliary Transport of Glutathione
}

\author{
MARJAN DIJKSTRA, FOLKERT KUIPERS,' RICK HAVINGA, EGBERT P. SMIT, \\ AND ROEL J. VONK
}

Department of Pediatrics, University of Groningen, Bloemsingel 10, $9712 \mathrm{KZ}$ Groningen, The Netherlands

\begin{abstract}
Bile secretion of trace elements, analyzed by proton-induced $x$-ray emission, was studied in rats with a congenital defect in hepatobiliary transport of organic anions [Groningen Yellow (GY) rats], in which the process of bile secretion resembles that of the neonatal period. Bile flow $(-41 \%)$ and biliary glutathione secretion $(-99 \%)$ were drastically impaired in GY rats compared with controls. Plasma concentrations of all detectable trace elements (Fe, $\mathrm{Cu}, \mathrm{Zn}, \mathrm{Mo}, \mathrm{Br}$, and $\mathrm{Se}$ ), as well as that of simultaneously determined $\mathrm{Ca}$, were similar in GY and age-matched control Wistar rats. Bile concentrations of $\mathrm{Fe}, \mathrm{Mo}, \mathrm{Br}$, and $\mathrm{Ca}$ were also similar in both groups, resulting in a $\sim 40 \%$ reduction of their secretion rates in GY rats. The concentrations of $\mathrm{Zn}(-62 \%)$ and $\mathrm{Mn}(-64 \%)$ were significantly lower in GY rats in contrast to that of $\mathrm{Cu}$, which was $50 \%$ higher. Se could not be detected in bile of either group. Recovery in bile (\% dose/3 h) after i.v. injection of $\mathrm{MnCl}_{2}, \mathrm{CuSO}_{4}$, or $\mathrm{SeO}_{2}(1 \mathrm{mg}$ metal $/ \mathrm{kg})$ was lower in GY rats than in controls: $\mathrm{Mn}, 26$ and $35 \% ; \mathrm{Cu}, 2.6$ and $5 \%$; and $\mathrm{Se}, 1.5$ and $5 \%$, respectively. Injection of $\mathrm{ZnSO}_{4}$ did not lead to increased $\mathrm{Zn}$ secretion in GY rats, and only $1.1 \%$ of the dose was recovered in controls. Thus, the hepatic handling of different endogenous and exogenously administered trace metals is affected to a variable extent in the GY rat. For a number of metals (e.g. Fe, Mo), this may be related to the reduced bile flow; for others $(e . g . \mathrm{Zn}$, $\mathrm{Mn}, \mathrm{Cu}$ ), other regulatory factors appear to be responsible. (Pediatr Res 28: 339-343, 1990)
\end{abstract}

\section{Abbreviations}

GSH, glutathione

GY, Groningen Yellow

PIXE, proton-induced $x$-ray emission

The immaturity of hepatic excretory function in the neonatal period is well established. Hepatobiliary transport of several organic anions (1) and of bile acids (2) is severely impaired in neonatal animals when compared with that in adults. In addition, bile flow is markedly reduced $(3,4)$. Bile is the main route for elimination of certain trace elements $(5,6)$. The mechanism(s) involved in transport of metals from hepatocytes into bile is largely undefined. GSH may play an important role in this

Received December 14, 1989; accepted May 2, 1990

Correspondence: Marjan Dijkstra, Department of Pediatrics, University of Groningen, Bloemsingel 10,9712 KZ Groningen, The Netherlands.

Supported by grant 900-562-036 from the Dutch Health Research Organization for Applied Scientific Research (Medigon) and the J. K. de Cock Stichting.

F.K. is a Research Fellow from the Royal Netherlands Academy of Arts and Sciences. process; in a series of papers (7), Ballatori and Clarkson have provided evidence that the bile secretion of mercury and of GSH are coupled in the rat. A role for GSH has also been suggested in the secretion of copper $(8)$, zinc $(8,9)$, silver $(10)$, chromium (11), and cadmium (12). Bile secretion of GSH occurs via a carrier-mediated transport system $(13,14)$, which is immature in the suckling rat and develops only at weaning (4).

A mutant rat strain, which has recently been bred and characterized in our laboratory $(15,16)$, provides a useful tool to study GSH-dependency of biliary metal secretion. These rats (GY strain) express a congenital defect in hepatobiliary transport of a variety of organic anions, including bilirubin diglucuronide (16), bile acid sulfates (16), and bile acid glucuronides (17), whereas transport of amino acid conjugated bile acids is not affected (15). Available data suggest that the defect is similar to that in the rat strain previously described by Jansen et al. (18). GSH is virtually absent in bile of these animals $(16,19)$, despite elevated hepatic GSH concentrations (19). Bile flow is reduced in GY rats due to a $53 \%$ reduction of the so-called bile acidindependent fraction of bile flow (15); this may, at least partly, be caused by the absence of GSH in bile (20). Overall, the process of bile formation in GY rats therefore resembles that described in neonatal animals $(2,3)$. The aim of our study was to compare bile secretion of endogenous and i.v. administered trace metals in GY and control rats, to gain an insight into the GSHdependency of these secretory processes.

\section{MATERIALS AND METHODS}

Animals. Male normal Wistar and GY Wistar rats weighing 280-300 g were used throughout the study. GY rats, bred at the Central Animal Laboratory of the University of Groningen, express a congenital defect in hepatobiliary transport of organic anions, resulting in conjugated hyperbilirubinemia. The rat strain has been described in detail elsewhere $(15-17)$. The rats were kept on a $12 \mathrm{~h}$ light- $12 \mathrm{~h}$ dark schedule and had free access to food and water before the experiments. Lab food (Hope Farms B.V., Woerden, The Netherlands) contained 195, 72, 63, and $22.4 \mathrm{mg} / \mathrm{kg}$ of iron, manganese, zinc, and copper, respectively. All experiments were performed according to the institutional guidelines for the care and use of laboratory animals in research.

Experimental procedures. Experiments were performed between 1100 and $1500 \mathrm{~h}$ to exclude effects of circadian variations in bile flow (21). The rats were anesthetized with sodium-pentobarbital ( $60 \mathrm{mg} / \mathrm{kg}$ body wt), and anesthesia was maintained by injection of small doses of the drug during the experiment. The rats were equipped with a silastic catheter (Silastic, Dow Corning, Midland, MI; inner diameter $0.5 \mathrm{~mm}$, outer diameter $0.94 \mathrm{~mm}$ ) in the jugular vein and in the common bile duct, as previously described (22). Body temperature was maintained at $37.5-38^{\circ} \mathrm{C}$ by means of a heating pad. Bile samples were collected in preweighed vials for a period of $4 \mathrm{~h}$ in 30-min fractions. After 
collection of two bile samples and a blood sample to assess baseline values, a solution of $\mathrm{MnCl}_{2}, \mathrm{CuSO}_{4}, \mathrm{ZnSO}_{4}$, or $\mathrm{SeO}_{2}$ in saline $(1 \mathrm{mg}$ metal $/ \mathrm{kg}$ body $\mathrm{wt}$, all obtained from $\mathrm{E}$. Merck, Darmstadt, FRG) was injected via the jugular vein catheter and bile collection was continued for another $3 \mathrm{~h}$. At $2 \mathrm{~h}$ after injection, a second blood sample was taken. Blood was centrifuged and bile and plasma samples were stored at $-20^{\circ} \mathrm{C}$ until analysis.

Analytical procedures. All vials and test tubes were washed with concentrated $\mathrm{HNO}_{3}$ and rinsed with bidistilled water before use. Bile production was determined gravimetrically, assuming a density of $1.0 \mathrm{~g} / \mathrm{mL}$ for bile. The concentrations of trace elements and of calcium were determined in a single sample by PIXE. PIXE analysis allows accurate determination of nonvolatile elements with $Z>19$ and an abundance exceeding $0.5 \mu \mathrm{g} / \mathrm{mL}$ in a single sample (23). Biliary concentrations of glutathione (GSH +2 GSSG) were determined according to Griffith (24).

Statistics. The statistical significance of differences between means was calculated using Wilcoxon's rank sum test; $p$ values $<0.05$ were regarded as significant.

\section{RESULTS}

The plasma and bile concentrations of detectable trace elements are given in Table 1 . Because the concentration of $\mathrm{Ca}$ is determined simultaneously by the PIXE procedure (23), values for this element are included for comparative purposes. As previously reported $(15,16)$, bile flow was significantly lower in GY rats than in controls. GSH concentrations were very low in bile of GY rats ( 0.005 versus $3.2 \mathrm{mM}$ in controls), as already described by us (16) and by others (19). Plasma concentrations of all detectable trace elements (Fe, $\mathrm{Cu}, \mathrm{Zn}, \mathrm{Mo}, \mathrm{Br}$, and $\mathrm{Se}$ ) as well as those of $\mathrm{Ca}$ were similar in control and GY Wistar rats (Table 1). The biliary concentrations of $\mathrm{Fe}, \mathrm{Mo}, \mathrm{Br}$, and $\mathrm{Ca}$ were also similar in both strains of rats. As a consequence, bile secretion of these elements was reduced in GY rats to an extent similar to the reduction in bile flow $(\sim 40 \%)$. The concentrations of $\mathrm{Mn}$ and $\mathrm{Zn}$ were significantly lower in bile of GY rats than in controls, whereas that of $\mathrm{Cu}$ was $51 \%$ higher. The output rate of endogenous $\mathrm{Cu}$ was, therefore, not significantly reduced in GY rats. $\mathrm{Mn}$ and Se were below detection limits in plasma and bile, respectively, in both strains of rats. Bile to plasma concentration ratio was very low with $\mathrm{Se}, \mathrm{Zn}$, and $\mathrm{Fe}$, but higher with $\mathrm{Mn}$. The concentrations of $\mathrm{Ca}, \mathrm{Mo}$, and $\mathrm{Br}$, however, were similar in plasma and bile. The bile to plasma concentration ratio for $\mathrm{Zn}$ was significantly lower in GY rats than in controls, whereas that for $\mathrm{Cu}$ tended to be higher. No significant differences were observed between the two strains of rats for the other elements.

Figure 1 shows the cumulative bile secretion of $\mathrm{Cu}, \mathrm{Mn}, \mathrm{Se}$, and $\mathrm{Zn}$ after i.v. administration of these metals to control and GY rats. In all experiments, cumulative excretion in bile was lower in GY rats than in controls. Mn was secreted very rapidly into bile; at $3 \mathrm{~h}$ after injection, $35 \%$ of the dose had already been secreted in controls and $23 \%$ in GY rats. Corresponding values for $\mathrm{Cu}$ were 5 and $2.6 \%$, and for Se, 4.5 and $1.5 \%$, respectively. Recovery of $\mathrm{Zn}$ was only $1.1 \%$ in controls and a large variation between animals was observed, whereas GY rats did not secrete exogenously administered $\mathrm{Zn}$ into bile. Removal rate of all metals from plasma appeared to be similar in both strains of rats (Fig. 2). Plasma Cu concentrations were very similar before and at $2 \mathrm{~h}$ after injection of $\mathrm{CuSO}_{4}$, and $\mathrm{Mn}$ was below detectable limits before and $2 \mathrm{~h}$ after its injection. In contrast, plasma concentrations of $\mathrm{Se}$ and $\mathrm{Zn}$ were still markedly elevated $2 \mathrm{~h}$ after administration of these metals (2.3-fold and 6-fold, respectively).

\section{DISCUSSION}

Biliary secretion is a principal pathway for elimination of a number of trace elements from the body, and this process may play a role in the homeostatic regulation of these elements. $\mathrm{Cu}$ represents the best known example of this class of elements; a blockade of hepatobiliary $\mathrm{Cu}$ transport, as in Wilson's disease (25), results in its hepatic accumulation and eventually leads to liver cell damage. Despite numerous investigations, the mechanism(s) of hepatobiliary metal transport is still poorly understood. Much research in the past two decades has been focused on the biliary elimination of i.v. administered mercury. It is now well established that under a variety of experimental conditions there is a close correlation between the secretion rates of GSH and those of inorganic mercury and methylmercury (7). The process is thought to proceed via intracellular formation of a metal-GSH complex, which is subsequently secreted into bile by the GSH-transporting system. This transport system is immature in the neonatal rat and develops only at weaning (4). As a consequence, suckling rats show a markedly reduced capacity to secrete mercury into bile (4). A role of GSH has also been proposed in bile secretion of a number of trace metals, including $\mathrm{Cu}, \mathrm{Zn}, \mathrm{Ag}$, and $\mathrm{Cr}(7-12)$. However, available evidence is limited, and differences may exist between hepatic handling of endogenous and exogenously administered metals (26). In addition, there may be multiple pathways for a certain metal to reach the bile canaliculus (27).

In our study, we have systematically evaluated the role of GSH in bile secretion of trace metals in the rat by combining the analytical technique of PIXE with the availability of a rat strain with a congenital defect in biliary GSH secretion. The molecular background of the secretory defect in GY rats has not yet been fully characterized. Yet, the process of bile formation in these animals resembles that described for the neonatal rat $(2,3)$.

The observation that the plasma concentrations of all detectable trace elements were very similar in GY and control rats,

Table 1. Plasma and bile concentrations, bile flow, and biliary output rates in GY Wistar rats relative to control Wistar rats*

\begin{tabular}{|c|c|c|c|c|c|}
\hline & \multicolumn{2}{|c|}{ Plasma concentration } & \multicolumn{2}{|c|}{ Bile concentration } & \multirow{2}{*}{$\begin{array}{c}\text { Biliary secretion } \\
\text { GY vs C }(\%)\end{array}$} \\
\hline & Control & GY & Control & GY & \\
\hline $\mathrm{Ca}$ & $3.3 \pm 0.3$ & $3.1 \pm 0.3$ & $3.0 \pm 0.9$ & $2.8 \pm 0.6$ & $-40 \dagger$ \\
\hline $\mathrm{Mn}$ & nd & nd & $5.0 \pm 1.5$ & $1.8 \pm 1.6 \dagger$ & $-78 \dagger$ \\
\hline $\mathrm{Fe}$ & $56.9 \pm 18.9$ & $47 \pm 14.1$ & $17.5 \pm 6.6$ & $19.7 \pm 6.2$ & -31 \\
\hline $\mathrm{Cu}$ & $25.8 \pm 6.9$ & $31.1 \pm 8.4$ & $26.4 \pm 3.5$ & $39.9 \pm 4.2 \dagger$ & -7 \\
\hline $\mathrm{Zn}$ & $30.0 \pm 6.0$ & $31.6 \pm 12.7$ & $6.8 \pm 3.4$ & $2.6 \pm 0.8 \dagger$ & $-80 \dagger$ \\
\hline Mo & $3.8 \pm 0.9$ & $3.4 \pm 1.1$ & $3.7 \pm 1.2$ & $4.0 \pm 1.1$ & $-39 \dagger$ \\
\hline $\mathrm{Br}$ & $136 \pm 27.9$ & $125 \pm 31.9$ & $131 \pm 30$ & $137 \pm 42$ & $-38 \dagger$ \\
\hline $\mathrm{Se}$ & $5.3 \pm 0.6$ & $5.6 \pm 1.4$ & nd & nd & \\
\hline
\end{tabular}

Bile flow

$1.38 \pm 0.21$

$0.81 \pm 0.19 \dagger$ $-41 \dagger$

${ }^{*}$ Concentration of $\mathrm{Ca}(\mathrm{mM})$ and trace elements $(\mu \mathrm{M})$ in plasma and bile; bile flow $(\mathrm{mL} / \mathrm{h})$. Values are mean $\pm \mathrm{SD}$. Controls $(\mathrm{C}), n=9 ; \mathrm{GY}$ rats (GY), $n=8$. nd, not detectable.

$\dagger$ Significantly different from controls. 


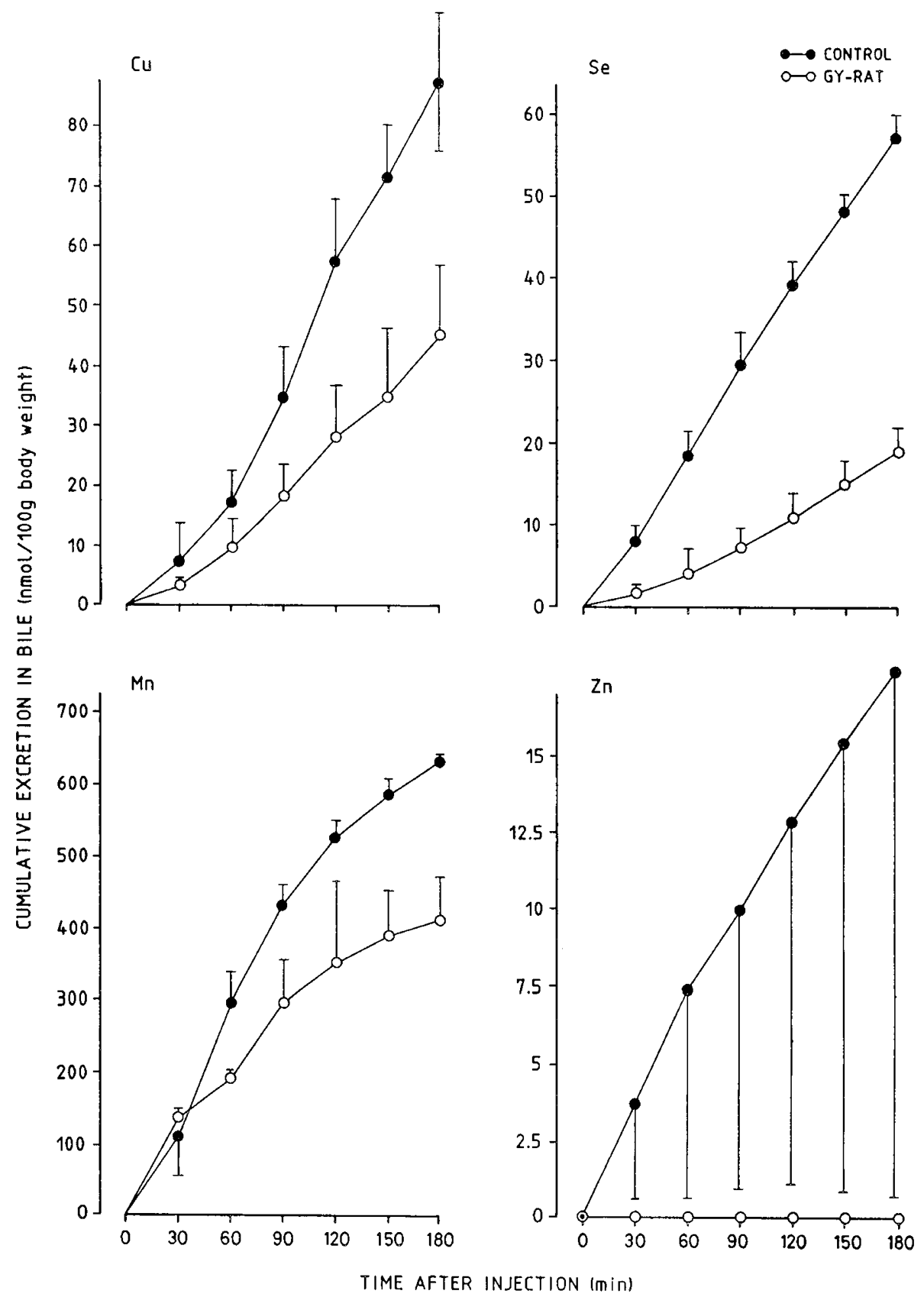

Fig. 1. Cumulative bile secretion of metals in GY (open circles) and control (closed circles) rats, after i.v. injection of $1 \mathrm{mg} / \mathrm{kg}$ of $\mathrm{Cu}, \mathrm{Se}, \mathrm{Mn}$, or Zn. $n=3$ in all experiments: bars indicate SD.

despite reduced bile secretion rates of most elements, indicates that the mutant animals are able to maintain their homeostasis. However, it should be kept in mind that plasma levels do not necessarily reflect the whole-body status of a metal. For a number of metals ( $\mathrm{Br}, \mathrm{Mo}$, and $\mathrm{Fe}$ ), as well as for $\mathrm{Ca}$, it was found that the biliary concentration in GY rats and control rats was virtually identical. As a result of the lower bile flow in the former, bile secretion of these elements was proportionally reduced. These data are in accordance with recent studies from our laboratory, in which it was shown that secretion rates of the mentioned elements closely follow changes in bile flow caused by variations in bile acid output (Dijkstra M, Kuipers F, Havinga R, Smit EP, de Vries JJ, Vonk RJ, unpublished data). This and the observed bile to plasma ratio of approximately 1 for $\mathrm{Br}, \mathrm{Mo}$, and $\mathrm{Ca}$ suggest that their secretion is largely attributable to the convective flow of water and soluble elements from plasma to bile induced by the osmotic forces generated by canalicular secretion of ions, such as bile acids. The low bile to plasma ratio of Fe may be caused by the fact that $\mathrm{Fe}$ in plasma is tightly bound to proteins (29) and is therefore not freely diffusible. However, it has been shown in rats that $\mathrm{Fe}$ is released from hepatocytic lysosomes into bile by exocytosis under the condition of dietary iron overload (31). It is possible that there is more than one pathway for biliary Fe secretion, and that the relative importance of these pathways depends upon the Fe status of the animal.

Biliary secretion of endogenous $\mathrm{Mn}$ and $\mathrm{Zn}$ in GY rats was impaired to a larger extent than bile flow was reduced. In the case of $\mathrm{Zn}$, this can probably be attributed to a strong GSHdependency of its bile secretion $(8,9)$, which is also evident from the observation that biliary $\mathrm{Zn}$ secretion did not increase after i.v. administration of $\mathrm{Zn}$ in $\mathrm{GY}$ rats. In control rats, only a very small fraction of injected $\mathrm{Zn}$ was eliminated via bile, which is in accordance with the concept that the main pathway for its elimination is not via bile but across the intestinal wall (31). It is 


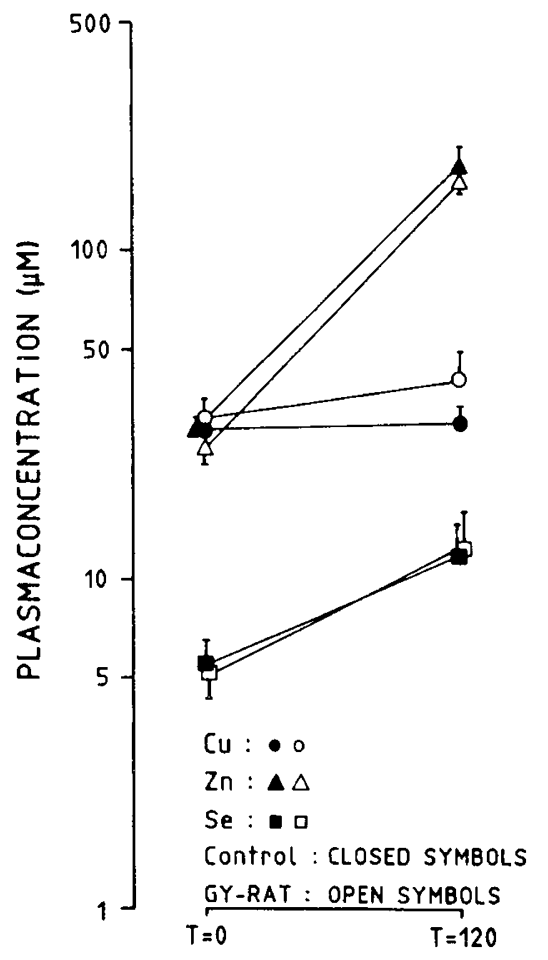

Fig. 2. Plasma concentrations of $\mathrm{Cu}(\bullet, O), \operatorname{Zn}(\boldsymbol{\Delta}, \Delta)$, and $\operatorname{Se}(\boldsymbol{\square}, \square)$ before $(T=0)$ and at $2 \mathrm{~h}(T=120)$ after i.v. administration of $1 \mathrm{mg} / \mathrm{kg}$ body wt of either metal to control (closed symbols) or GY rats (open symbols). Mn was below detection limits both before and $2 \mathrm{~h}$ after administration of this metal. $n=3$ in all experiments; bars indicate SD.

well established that $\mathrm{Mn}$ is very rapidly secreted into bile in adult animals (32). Available data suggest that active transport processes are involved in Mn secretion (33), although these processes have not yet been characterized. Association with bile pigments has been suggested to play a role in Mn secretion (34). It is therefore possible that impaired $\mathrm{Mn}$ secretion in GY rats is related to retention of conjugated bilirubin in the livers of these animals. The genetic defect in GY rats may thus indirectly inhibit Mn disposition into bile; the observation that secretion of endogenous and exogenous $\mathrm{Mn}$ is not affected to the same degree in GY rats suggests that different processes may operate in removal of $\mathrm{Mn}$ from the different sources. Plasma levels of $\mathrm{Mn}$ below detection limits in both strains of rats, even after i.v. Mn administration, probably result from the very efficient hepatic clearance of this element $(6,32)$.

Se could not be detected in bile under basal conditions, in agreement with experimental data that it is mainly eliminated via urine (6). However, a substantial amount of Se was secreted into bile after i.v. injection of $\mathrm{Se}$ in control rats, indicating that under conditions of Se excess the biliary pathway becomes of quantitative importance. From our data, we cannot conclude whether under these conditions impaired Se secretion in GY rats is due to reduced bile flow, absence of biliary GSH, or both.

The only element for which basal bile secretion was not significantly impaired in GY rats was $\mathrm{Cu}$; its higher bile concentration compensated for the lower bile flow in these animals. This clearly indicates that secretion of endogenous $\mathrm{Cu}$ can proceed independently of GSH. Our data therefore do not support the conclusions of Alexander and Aaseth (8), who reported a decrease of endogenous $\mathrm{Cu}$ secretion after treatment of rats with diethylmaleate to deplete hepatic and biliary GSH. However, we found that secretion of exogenously administered $\mathrm{Cu}$ was markedly impaired in GY rats. This, together with our recent observation that a similar inhibition of exogenous $\mathrm{Cu}$ secretion occurs in control rats pretreated with diethylmaleate (26), suggests that
GSH is required for efficient removal of excess $\mathrm{Cu}$ from the body. Apparently, multiple pathways exist for biliary output of $\mathrm{Cu}$, which depend to a varying degree on GSH secretion. It is therefore conceivable that in situations with impaired GSH secretion-for instance, in the neonatal period-the liver is more susceptible to damaging effects of $\mathrm{Cu}$ overload.

Acknowledgments. The authors thank Lodewijk Martijn and Bert Tebbes for preparing the figures.

\section{REFERENCES}

1. Klaassen CD 1973 Hepatic excretory function in the newborn rat. J Pharmacol Exp Ther 184:721-728

2. Balistreri WF 1983 Immaturity of hepatic excretory function and the ontogeny of bile acid metabolism. J Pediatr Gastroenterol Nutr 2:S207-S2 14

3. Gregus Z, Stein AF, Klaassen CD 1987 Age dependent biliary excretion of glutathione related thiols in rats: role of $\tau$-glutamyltransferase. Am J Physiol 253:G86-G92

4. Ballatori N, Clarkson TW 1982 Developmental changes in the biliary excretion of methyl mercury and glutathione. Science 216:61-63

5. Klaassen CD, Watkins JB 1984 Mechanisms of bile formation, hepatic uptake, and biliary excretion. Pharmacol Rev 36:1-67

6. Gregus Z, Klaassen CD 1986 Disposition of metals in rats: a comparative study of fecal, urinary, and biliary excretion and tissue distribution of eighteen metals. Toxicol Appl Pharmacol 85:24-38

7. Ballatori N, Clarkson TW 1985 Biliary secretion of glutathione and glutathionemetal complexes. Fundam Appl Toxicol 5:816-831

8. Alexander J, Aaseth $\mathrm{J} 1980$ Biliary excretion of copper and zinc in the rat as influenced by diethylmaleate, selenite and diethyldithiocarbamate. Biochem Pharmacol 29:2129-2133

9. Alexander J, Aaseth J, Refsvik $\Upsilon 1981$ Excretion of zinc in rat bile: a role of glutathione. Acta Pharmacol Toxicol 49:190-194

10. Alexander J, Aaseth J 1981 Hepatobiliary transport and organ distribution of silver in the rat as influenced by selenite. Toxicology 21:179-186

11. Norseth T, Alexander J, Aaseth J, Langards S 1982 Biliary excretion of chromium in the rat: a role of glutathione. Acta Pharmacol Toxicol 51:450455

12. Cherian MG, Vostal JJ 1977 Biliary excretion of cadmium in the rat I: dose dependent biliary excretion and the form of cadmium in the bile. $\mathrm{J}$ Toxicol Environ Health 2:945-954

13. Inoue M, Kinne R, Tran T, Arias IM 1983 The mechanism of biliary secretion of reduced glutathione: analysis of transport process in isolated rat liver canalicular membrane vesicles. Eur J Biochem 134:467-471

14. Akerboom TPM, Inoue M, Sies H, Kinne R, Arias IM 1984 Biliary transport of glutathione disulfide studies with isolated rat liver canalicular membrane vesicles. Eur J Biochem 141:211-215

15. Kuipers F, Enserink M, Havinga R, van der Steen ABM, Hardonk MJ, Fevery J, Vonk RJ 1988 Separate transport systems for biliary secretion of sulfated and unsulfated bile acids in the rat. J Clin Invest 81:1593-1599

16. Kuipers F, Enserink M, Havinga R, van der Steen ABM, Hardonk MJ, Fevery J, Vonk RJ 1989 Separate transport systems for biliary secretion of sulfated and unsulfated bile acids in the rat. In: Paumgarter G, Stiehl A, Gerok W (eds) Trends in Bile Acid Research. Kluwer Academic Publishers, Lancaster, pp 143-152

17. Kuipers F, Radominska A, Zimniak P, Little JM, Havinga R, Vonk RJ, Lester R 1989 Defective biliary secretion of bile acid 3-O-glucuronides in rats with hereditary conjugated hyperbilirubinemia. J Lipid Res 30:1835-1845

18. Jansen PLM, Peters WHM, Lamers WH 1985 Hereditary conjugated hyperbilirubinemia in mutant rats caused by defective hepatic anion transport. Hepatology 5:573-579

19. Oude Elferink RPJ, Ottenhoff R, Liefting W, de Haan J, Jansen PLM 1989 Hepatobiliary transport of glutathione and glutathione conjugate in rats with hereditary hyperbilirubinemia. J Clin Invest 84:476-483

20. Ballatori N, Truong AT 1989 Relation between biliary glutathione excretion and bile acid-independent bile flow. Am J Physiol 256:G1-G7

21. Vonk RJ, van Doorn ABD, Strubbe J 1978 Bile secretion and bile composition in the freely moving rat. Clin Sci Mol Med 55:253-259

22. Vonk RJ, Danhof M, Coenraads T, van Doorn ABD, Keulemans K, Scaf A, Meijer DKF 1979 The influence of bile salts on the hepatic transport of the organic anion dibromosulphthalein (DBSP). Am J Physiol 237:E524-E534

23. Boerma DO, Smit EP, Roosnek N 1989 PIXE trace element determination and its accuracy in the analysis of bile. Nuclear Instruments and Methods in Physics Research B 36:60-73

24. Griffith OW 1980 Determination of glutathione and glutathione disulfide using glutathione reductase and 2-vinyl pyridine. Anal Biochem 106:207-212

25. Sternlieb I 1980 Copper and the liver. Gastroenterology 78:1615-1628

26. Houwen RJ, Dijkstra M. Kuipers F, Smit EP, Havinga R, Vonk RJ 1990 Two pathways for biliary copper excretion in the rat. The role of glutathione. 
Biochem Pharmacol 39:1039-1044

27. Kressner MS. Stockert RJ, Morell AG, Sternlieb I 1984 Origins of biliary copper. Hepatology 4:867-870

28. Deleted in proof

29. Bacon BR, Tavill AS 1984 Role of the liver in normal iron metabolism. Semin Liver Dis 4:181-194

30. LeSage GD. Kost LJ. Barham SS, LaRusso NF 1986 Biliary excretion of iron from hepatocyte lysosomes in the rat. J Clin Invest 77:90-97
3I. Solomons NW. Cousins RJ 1984 Zinc. In: Solomons NW. Rosenberg IH (eds) Absorption and Malabsorption of Mineral Nutrients. Liss. New York, pp 125-197

32. Klaassen CD 1974 Biliary excretion of manganese in rats, rabbits and dogs. Toxicol Appl Pharmacol 29:458-468

33. Klaassen CD 1976 Biliary excretion of metals. Drug Metab Rev 5:165-196

34. Cikrt M, Tichy M 1972 Polyacrylamide disc gelelectrophoresis of ${ }^{52} \mathrm{MnCl}_{2}$, ${ }^{64} \mathrm{CuCl}_{2},{ }^{203} \mathrm{HgCl}_{2}$ and ${ }^{210} \mathrm{~Pb}\left(\mathrm{NO}_{3}\right)_{2}$. Experientia $28: 383-384$ 